\title{
A fulminant course of Cronkhite-Canada syndrome
}

A 57-year-old man suffered from watery diarrhea, weight loss, and abdominal pain for 4 months. Noticeable signs of nail dystrophy (onychomadesis of all nails) were present ( $\bullet$ Fig. 1 a) along with alopecia and cutaneous foci of hyperpigmentation ( $\bullet$ Fig. 1 b).

Upper-gastrointestinal endoscopy revealed a large number of strawberry-like polyps of different size in the stomach (๑ Fig. 2).

Colonoscopy revealed polyposis of the whole colon, including the rectum. The majority of the polyps had a strawberrylike, adenomatous, and hyperplastic appearance $(\bullet$ Fig. 3$)$.

Histologically, the majority of the polyps were juvenile-like with cystic dilatations of the glands and a benign mucinous epithelium. The glands were filled with a large amount of mucin ( $\bullet$ Fig. 4).

Some adenomatous polyps with lowgrade dysplasia in the colon were also detected. A subsequent enteroscopy did not find polyps; however, edema and small indentation of the jejunum were present. Immunohistochemistry showed total alactasia and a strong positivity for tumor necrosis factor (TNF) in the macrophages and lymphocytes. Based on both the clinical and endoscopic picture, a diagnosis of Cronkhite-Canada syndrome was established.

Despite complex treatment, the clinical course was unfavourable. Since the clinical state of the patient did not improve, anti-TNF- $\alpha$ treatment was considered. TNF- $\alpha$ activity was examined in the small-intestinal mucosa, and the results showed a strong intracellular expression of TNF- $\alpha$. Unfortunately, an experimental anti-TNF- $\alpha$ treatment could not be introduced, because of the rapid progression of the disease. The patient died 4 months after the diagnosis of Cronkhite-Canada syndrome was established.

\section{Video 1}

Endoscopy of the stomach.

\section{Video 2}

Endoscopy of the colon.

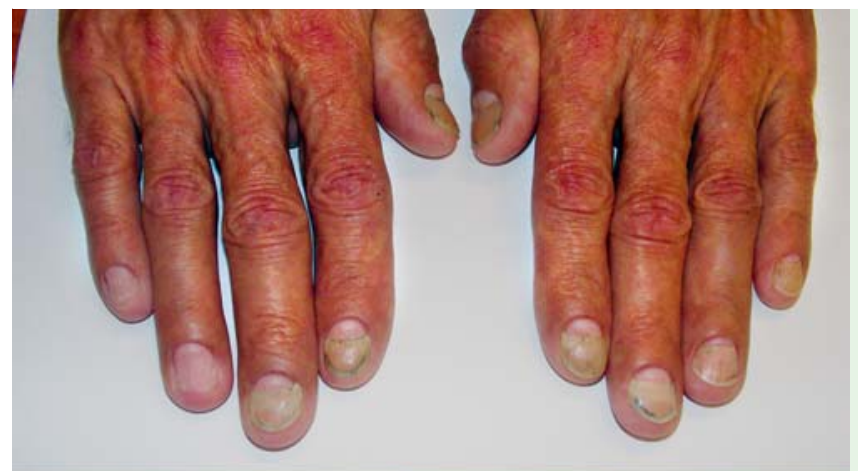

Fig. 1 Main physical findings. a All 20 nails with onychomadesis about $3 \mathrm{~mm}$ from the lunula. Several nail plates have been lost. b Hands with several small foci of skin hyperpigmentation.
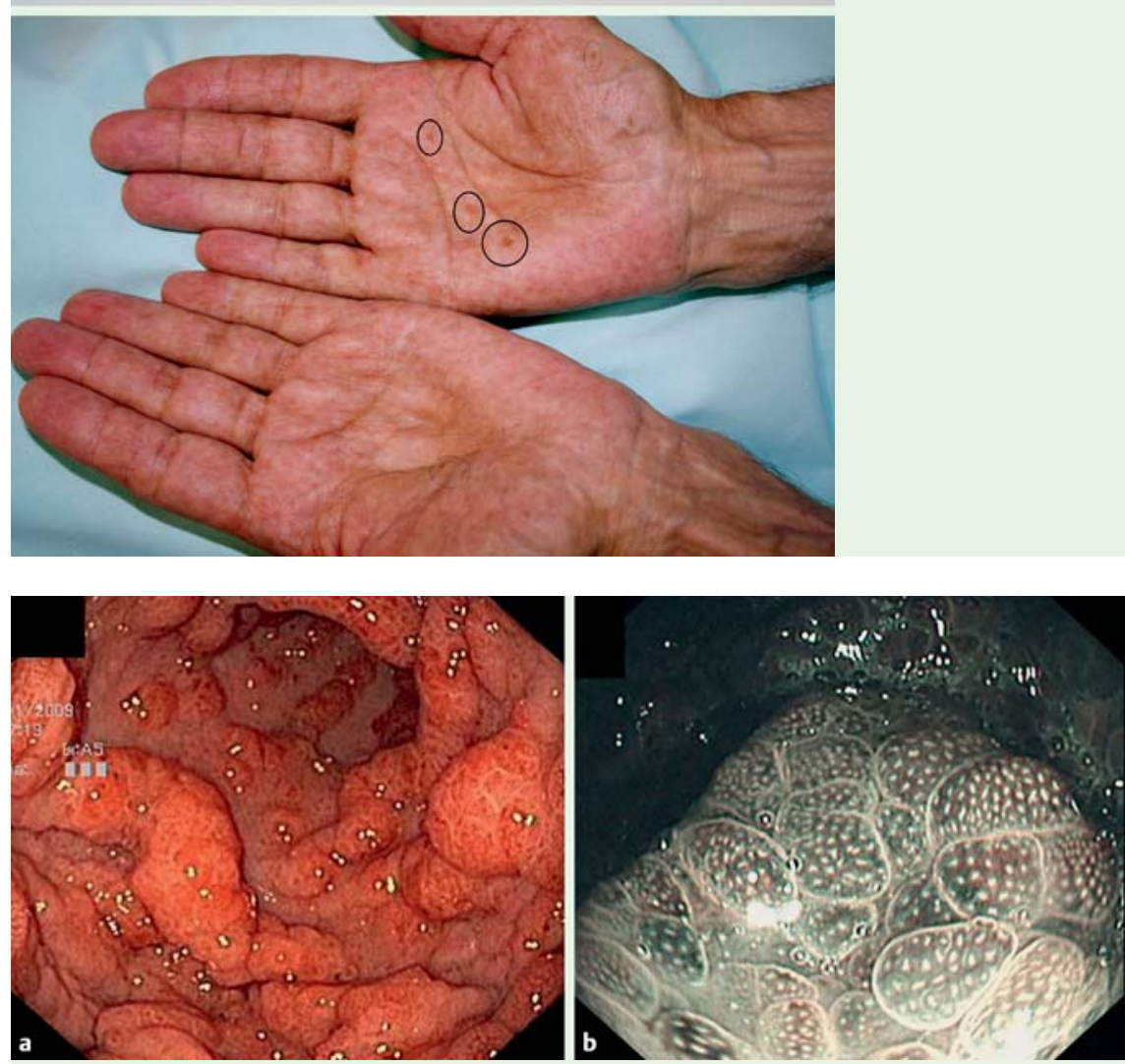

Fig. 2 Endoscopic findings in the stomach. a Polyps of gastric body and antrum. $\mathbf{b}$ Detailed view of gastric polyp using zoom and narrow-band imaging mode; note the strawberry-like appearance.
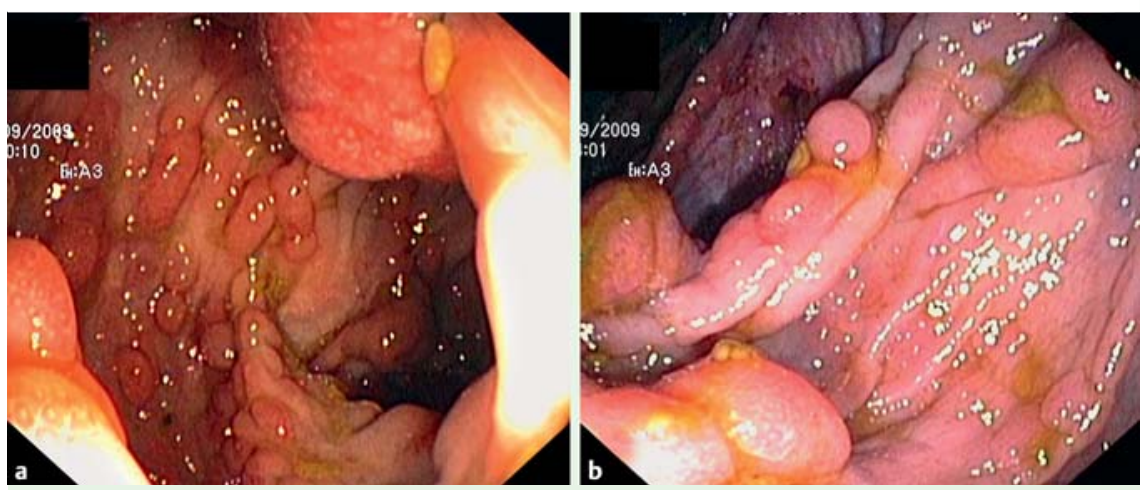

Fig. 3 a, b Endoscopic view of colonic polyps. 


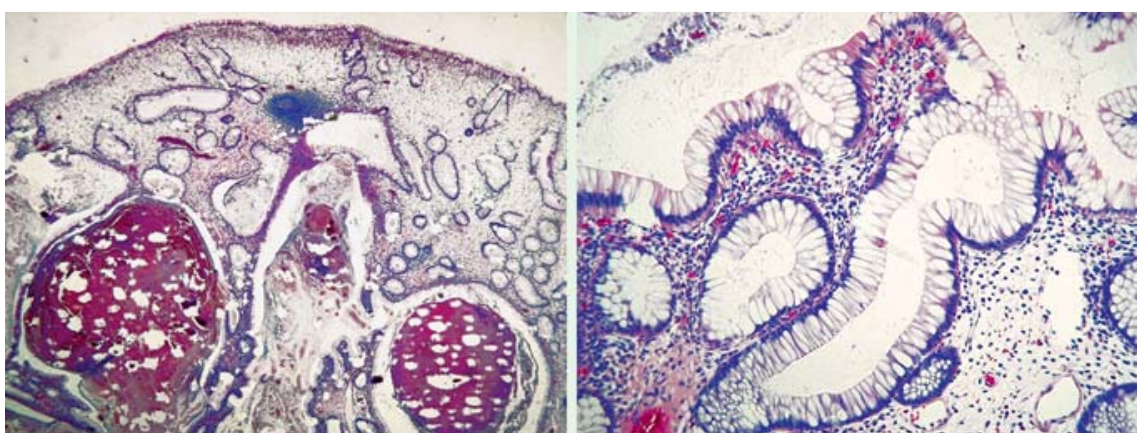

Fig. 4 Histology. a Juvenile-like polyp with enlarged mucin glands. b Detailed view of mucinous glandular epithelium.

Cronkhite-Canada syndrome is a rare non-hereditary polyposis syndrome of an unknown, possibly autoimmune etiology. The prognosis is poor and more than $50 \%$ of patients die within $2-4$ years $[1,2]$. Cronkhite-Canada syndrome should be considered in all patients with gastrointestinal polyposis together with emergent alopecia and/or nail dystrophy [3].

\section{Competing interests: None}

Endoscopy_UCTN_Code_CCL_1AD_2AC

\section{References}

1 Tao K, Patel JK, Pampati V. Cronkhite-Canada syndrome: a case report and review of the literature. Gastroenterol Res Pract 2009; Article ID 619378

2 Goto A. Cronkhite-Canada syndrome: epidemiological study of 110 cases reported in Japan. Nippon Geka Hokan 1995; 64: 3-14

3 Kojima E, Tomita A, Matsumura M, Kinoshita $I$. Magnifying the endoscopic appearance of Cronkhite-Canada syndrome. Gastrointest Endosc 2009; 70: 1242 -1243

\section{Bibliography}

DOI $10.1055 / \mathrm{s}-0030-1256003$

Endoscopy 2010; 42: E350-E351

(c) Georg Thieme Verlag KG Stuttgart · New York . ISSN 0013-726X

\section{P. Vankova ${ }^{3}$, I. Tuckova $^{2}$, M. Zavoral ${ }^{1}$}

. Martinek ${ }^{1}$, T. Chvatalova ${ }^{1}$, F. Zavada

${ }^{1}$ Charles University in Prague, Department of Internal Medicine, First Faculty of Medicine and Central Military Hospital, Praha, Czech Republic

2 Department of Pathology, Central Military Hospital, Praha, Czech Republic

3 Department of Gastroenterology, Jablonec Hospital, Jablonec nad Nisou, Czech Republic

\section{Corresponding author}

\section{J. Martinek, MD, PhD}

Department of Internal Medicine

Central Military Hospital

U Vojenská nemocnice 1200

Praha 6

Czech Republic

jan.martinek@volny.cz 